\title{
INTERCULTURALIDADE E INTERNACIONALIZAÇÃO EM TEMPOS DE GLOBALIZAÇÃO NEOLIBERAL: DESAFIOS, COMPLEXIDADES E POSSIBILIDADES
}

Interculturality and Internationalization in Times of Neoliberal Globalization: Challenges, Complexities, and Possibilities.

\author{
Francesca DELL'OLIO (USP) ${ }^{1}$ \\ Juliana Zeggio MARTINEZ (UFPR) ${ }^{2}$
}

\begin{abstract}
RESUMO: O objetivo deste texto está em resgatar parte das discussões vivenciadas em uma das "Rodas de Conversa" do FICLLA por meio da problematização e da reflexão de interculturalidade e internacionalização, que são definidos por nós a partir do conceito de colonialidade. Informadas pelo grupo latino-americano de colonialidade/modernidade, apresentamos e discutimos o conceito de colonialidade como um conceito e uma perspectiva onto-epistêmica que explica as hierarquias histórico-sociais e as relações desiguais de poder entre os vários elementos que nos constituem: língua, cultura, saberes, raça, gênero, classe social, etc. Ainda, buscamos apontar como a globalização e o capitalismo neoliberal estão imbricados na colonialidade e como este entrelaçamento - entre colonialidade/modernidade e globalização/neoliberalismo - fundamenta a lógica de sistema-mundo $^{3}$ da qual somos parte. Fazendo uso de duas situações problematizadoras, discutimos como a internacionalização e a interculturalidade se materializam em práticas de mobilidade e são informadas pela colonialidade na globalização neoliberal. Após os desafios e as complexidades exploradas ao longo do texto, finalizamos este artigo apontando possibilidades éticas necessárias diante da impossibilidade de zerarmos a História e/ou apagarmos a colonialidade.
\end{abstract}

PALAVRAS-CHAVE: colonialidade; globalização; interculturalidade; internacionalização.

\footnotetext{
${ }^{1}$ Pesquisadora independente. Doutora em Letras pela Universidade de São Paulo (USP) no Programa de Estudos Linguísticos e Literários em Inglês. fran.dellolio@gmail.com

2 Professora no Curso de Letras na Universidade Federal do Paraná (UFPR). Doutora em Letras pela Universidade de São Paulo (USP) no Programa de Estudos Linguísticos e Literários em Inglês. jumartinez@ufpr.br

${ }^{3}$ Sistema-mundo foi um conceito cunhado pelo sociólogo Immanuel Wallerstein e dialoga diretamente com o conceito de colonialidade do poder, cunhado por Aníbal Quijano. Ambos os pesquisadores consideravam a dependência existente entre nações, culturas, povos e economias; ambos buscaram explicar em suas pesquisas como a justaposição entre economia capitalista global e soberania dos Estados-nação ocorre, rompendo com a ideia de que estados nacionais sejam soberanos. Ao longo do texto, conforme o imbricamento entre colonialidade, capitalismo, globalização e neoliberalismo foram sendo explorados, esperamos que a compreensão de sistema-mundo seja mais visível.
} 


\begin{abstract}
The aim of this paper is to continue the discussions experienced in one of the "Group Discussions" at FICLLA through the problematization and reflection of interculturality and internationalization, which we understand from the concept of coloniality. Drawing on the latin-american group of coloniality/modernity, we present and discuss the concept of coloniality as a concept and an onto-epistemic perspective that explains the historical-social hierarchies and unequal power relations among the various elements which constitute us: language, culture, knowledges, race, gender, social class, etc. Moreover, we point out how globalization and neoliberal capitalism are intertwined in coloniality and how this entanglement - between coloniality/modernity and globalization/neoliberalism - underpins the worldsystem logic of which we are part. By using two problematizing situations, we discuss how internationalization and interculturality turn into mobility practices and are informed by coloniality in neoliberal globalization. After the challenges and complexities raised throughout the text, we conclude it by pointing out necessary ethical possibilities due to the impossibility of resetting History and/or erasing coloniality.
\end{abstract}

KEYWORDS: coloniality; globalization; interculturality; internationalization.

\title{
CONSIDERAÇÕES INICIAIS
}

A proposta deste trabalho surgiu da experiência que vivenciamos durante a preparação de uma das "Rodas de Conversa" do FICLLA ${ }^{4}$ e, posteriormente, no momento de realização desta Roda, quando colocamos nossas reflexões sobre interculturalidade e internacionalização em diálogo com o público participante do evento. Nossa "Roda de Conversa" foi preparada a oito mãos: por nós duas, que escrevemos este texto, e por outras duas amigas, Adriana da Silva Araújo (UFAM) e Martha Júlia Martins de Souza (UFRR), que também estiveram no FICLLA. A vontade de trabalharmos juntas, em algo comum, era resultado dos estudos que já vínhamos realizando durante nossas pesquisas de doutorado na Universidade de São Paulo, sob a orientação do Professor Dr. Lynn Mario T. Menezes de Souza. A conclusão de nossos doutoramentos foi em épocas muito próximas, o que nos oportunizou, felizmente, a convivência e a muitas reflexões coletivas a partir das discussões e das leituras que fazíamos em nosso grupo de estudos. Nossas pesquisas, portanto, tratam de questões específicas, mas se encontram na reflexão e nos questionamentos que temos sobre esta atualidade de nossas sociedades conhecida e denominada por globalização

\footnotetext{
${ }^{4}$ Fórum Internacional de Cultura, Literatura e Linguística Aplicada, UFPR, 2018.
} 
neoliberal. Além disso, como somos todas professoras, sempre tivemos preocupações em relação aos efeitos e às implicações da globalização neoliberal no âmbito educacional, especialmente no que concerne ao ensino de línguas (maternas, não-maternas, estrangeiras, etc.) e, mais recentemente, à internacionalização da Educação Superior.

Partimos da compreensão de que, na atual globalização neoliberal, políticas de multiculturalismo e de internacionalização da educação estão cada vez mais em evidência. Nas últimas décadas, governos e instituições buscam formas de responder às demandas da globalização, bem como lidar com línguas e culturas justapostas e em convivência tanto dentro de uma mesma nação quanto entre diferentes nações. Neste cenário, em geral, o conceito de globalização refere-se a um fenômeno recente e multifacetado, que desemboca na interdependência de economias devido às novas tecnologias, à diminuição dos custos de mobilidade e dos sistemas de comunicação que permitem diversos fluxos ocorrerem. Para nós, entretanto, globalização e neoliberalismo deveriam também ser analisados pela perspectiva da colonialidade, ou seja, diante da hierarquização e da desigualdade de raça, classe, gênero, culturas, línguas, saberes, entre outros elementos que nos constituem e atravessam as relações internacionais e interculturais.

No cenário atual de migrações e internacionalização da Educação Superior, por exemplo, o interesse pela mobilidade e pelos fluxos parece ser mais imediato enquanto a complexidade das relações interculturais parece esquecida, pois dificilmente encontramos espaços de discussão sobre as desigualdades que existem e permitem que práticas migratórias e de internacionalização tomem forma. É por essa razão que nossa discussão entrelaça internacionalização, interculturalidade e globalização. Entendemos, portanto, que é premente considerar os moldes epistêmicos sobre os quais se fundamenta o pensamento da modernidade/colonialidade; pensamento este que sustenta a atual globalização neoliberal e, consequentemente, propostas de educação internacional e intercultural. A nosso ver, internacionalização e interculturalidade estão atravessadas por ideologias e relações desiguais entre povos, línguas, culturas, saberes, e por isso demandam análises mais complexas que ultrapassem a ingênua celebração do encontro entre diferentes no cenário atual. Entendemos que em espaços de justaposição de línguas, povos e culturas existe sempre a possibilidade de trocas produtivas de saberes e vivências; no entanto, tal troca 
requer uma perspectiva ética de sociedade, de educação, de internacionalização e de interculturalidade.

Como professoras e pesquisadoras, neste artigo, pretendemos explorar e problematizar desafios, complexidades e possibilidades da atualidade neoliberal considerando o imbricamento entre colonialidade, globalização e interculturalidade na sociedade do conhecimento. A partir de uma perspectiva ética, acreditamos na urgência de se pensar em alternativas aos sistemas epistêmicos moderno/coloniais que fundamentam as sociedades ocidentais atuais. Para fazer tal reflexão emergir em conjunto com nossos leitores, propomos neste texto uma dinâmica parecida com a realizada no FICLLA. Primeiramente, apresentamos e discutimos alguns dos conceitos que consideramos fundamentais para nossa reflexão e discussão, e, logo em seguida, trazemos duas situações problematizadoras que construímos para a discussão durante a "Roda de Conversa" do evento. Acreditamos que essas situações problematizadoras podem nos ajudar a refletir sobre as complexidades da colonialidade e da globalização neoliberal de uma forma mais concreta, diretamente relacionadas à vida e, portanto, dando outros sentidos aos nossos estudos "meramente acadêmicos" diante das implicações que apresentam.

\section{ALGUNS CONCEITOS QUE FUNDAMENTAM NOSSA PROPOSTA}

Nosso ponto de partida pauta-se nos estudos do grupo latino-americano modernidade/colonialidade ${ }^{5}$. Para os autores e pesquisadores deste grupo - e.g. Quijano, Dussel, Mignolo, Grosfoguel, Castro-Gómez, Maldonado-Torres, Alcoff, Escobar, Sousa Santos, Walsh, entre outros ${ }^{6}$-, colonialidade e modernidade não existem de forma separada

\footnotetext{
5 "Segundo o antropólogo colombiano Arturo Escobar (2007), a genealogia do grupo inclui debates em teologia da libertação, filosofias e ciências sociais latino-americanas nas décadas de 1960 e 1970; os debates latino-americanos de modernidade e pós-modernidade na década de 1980; seguidos por discussões de estudos culturais, antropológicos e de comunicação na década de 1990. Santiago Castro-Gómez, filósofo colombiano, e Ramón Grosfoguel, sociólogo porto-riquenho (2007), relatam que, desde o final do século XX, o grupo encontra-se ativo, em cooperação acadêmica, envolvido em uma sequência de produções e de discussões acadêmicas e políticas com uma extensa área de temáticas, com trabalhos voltados às heranças coloniais na/da América Latina, à filosofia da libertação, aos estudos e teorias pós-coloniais, aos debates e análises do sistema-mundo. Trata-se de uma comunidade de argumentação, como definiu Escobar (2007), por isso também há, certamente, desacordos e tensões entre seus participantes” (MARTINEZ, 2017, p. 38-39).

${ }^{6}$ Ressaltamos que esses autores se encontram em uma perspectiva epistemológica e não geográfica, ou seja, tratam das epistemologias do Sul, independentemente de onde se localizam geograficamente.
} 
ou isolada. O termo colonialidade, cunhado pelo sociólogo peruano Aníbal Quijano no final da década de 90, foi incorporado por esse coletivo de pensadores latino-americanos, ampliando, ao longo das últimas décadas, sua conceitualização. Para este grupo, o objetivo central deste trabalho conceitual está em apontar a construção do projeto de modernidade ao mesmo tempo em que resgata e faz tornar visível seu lado oculto. Entende-se, entretanto, que esta proposta conceitual não é totalitária e homogênea, apesar de questionar a mesma lógica monocêntrica capitalista.

Colonialidade é um conceito ligado ao colonialismo - como foi pensado nos anos da Guerra Fria e da descolonização de muitas ex-colônias ao redor do mundo - mas não se trata da mesma coisa; a colonialidade nos ajuda a expandir nossa compreensão do colonialismo, levando em consideração seu legado. Seguindo Quijano (2007, p. 170), “a colonialidade é caracterizada como a forma mais comum de dominação no mundo, já que o colonialismo como uma ordem política explícita terminou". A colonialidade, portanto, não se refere unicamente aos momentos históricos de conquista e de ocupação de terras ameríndias por parte dos europeus; a colonialidade é o que nomeia e instaura a lógica da civilização ocidental, a partir do chamado Renascimento até a atualidade, da qual o colonialismo é uma dimensão constituinte, localizada no espaço e no tempo (MIGNOLO, 2007).

É nesse sentido que, de acordo com os pensadores latino-americanos, a colonialidade é o lado obscuro da modernidade, ou seja, esta última é pensada como uma narrativa complexa, cuja origem localiza-se na conquista da Europa na América Latina e no Caribe, que, celebrando sua vitória, construiu a civilização ocidental, escondendo, no entanto, seu lado mais obscuro, a colonialidade. Colonialidade e modernidade, portanto, não podem ser consideradas separadamente, pois a primeira é constitutiva da segunda (MIGNOLO, 2007). Isso significa dizer que a hierarquização étnico-racial, de trabalho, culturas, saberes e línguas que se formou na época do colonialismo ainda permanece em nossa atualidade, pois se transformaram as formas de dominação, mas se mantiveram as estruturas das relações centro-periferia em escala mundial.

Desse modo, as relações de superioridade e de inferioridade que se estabelecem e marcam os mais diferentes elementos que nos constituem (língua, cultura, saberes, raça, 
gênero, classe) estão presentes em nossas vidas atualmente não meramente por serem fruto de quaisquer relações de poder, mas pela diferença colonial que nos constitui (MIGNOLO, 2013) bem como por um padrão histórico de poder caracterizado pela co-presença de dominação, exploração e conflito (QUIJANO, 2002). É neste cenário onto-epistêmico ${ }^{7}$ da colonialidade que a globalização se encontra como um projeto de sociedade.

\begin{abstract}
O atual padrão de poder mundial consiste na articulação entre: 1) a colonialidade do poder, isto é, a idéia de "raça" como fundamento do padrão universal de classificação social básica e de dominação social; 2) o capitalismo, como padrão universal de exploração social; 3) o Estado como forma central universal de controle da autoridade coletiva e o moderno Estado-nação como sua variante hegemônica; 4) o eurocentrismo como forma hegemônica de controle da subjetividade/intersubjetividade, em particular no modo de produzir conhecimento (QUIJANO, 2002, p. 04).
\end{abstract}

A experiência da colonização, portanto, marcou a fundação de práticas de hierarquização e de desigualdade expressas na raça, gênero, classe, língua, saber, cultura, etc. (CASTRO-GÓMEZ; GROSFOGUEL, 2007) e que atualmente são os elementos basilares que sustentam a organização e a lógica do capitalismo neoliberal na atual globalização. Colonialidade e capitalismo estão profundamente entrelaçados ao longo deste projeto ambicioso de poder na história da humanidade (MALDONADO-TORRES, 2007) e, por essa razão, globalização, capitalismo e neoliberalismo são termos que podem e devem ser repensados e conceituados a partir da compreensão de colonialidade.

De acordo com Quijano (2002), apesar do termo globalização ser amplamente debatido e conceituado de diferentes formas, ainda parece haver certo consenso na compreensão de globalização como algo que gera uma fluida integração econômica, política e cultural entre diferentes nações, povos e culturas. Essa tácita aceitação contida na palavra integração acaba por desembocar no que compreendemos ser o global. Quijano (2002) explica que essa compreensão de uma "integração global" estava expressa nas mudanças de tempo e de espaço quando, diante dos novos sistemas de comunicação e da diminuição das distâncias com as novas tecnologias, passamos a aceitar a ideia de que "o

\footnotetext{
${ }^{7}$ A nosso ver, ontologia e epistemologia não estão separadas, pois consideramos que a diferença colonial que nos constitui reside na impossibilidade de separarmos o que sabemos (epistêmico) de quem somos (ontológico). Essa compreensão, além de pautada no conceito de colonialidade, está baseada na compreensão de que todos os conhecimentos são situados/localizados (situated-knowledges), portanto, independentes de seus sujeitos (HARAWAY, 1988).
} 


\section{Dossiê Especial F ICLLA}

REVISTA X, Curitiba, volum e 14, n.5,p. 82-105, 2019

mundo ficou menor", que o mundo se tornou simultâneo por conta da integração do tempo. E foi assim que “[a] famosa imagem de 'aldeia global' foi, sem dúvida, a construção mental inicial exitosa que dava conta dessa nova relação subjetiva com o espaço e com o tempo" (QUIJANO, 2002, p. 06).

Os pesquisadores latino-americanos, entretanto, ressaltam que ao analisarmos as consequências e os impactos dessa tal "integração global”, percebemos que o capitalismo e a globalização afetam diretamente a política global de distribuição de renda, de bens e serviços básicos e os próprios fluxos de capital (QUIJANO, 2002), deixando muito claro que as desigualdades e as distâncias entre povos e culturas não diminuíram, mas crescem a cada dia (SOUSA SANTOS, 2010); o que não é difícil de enxergar quando consideramos o aumento da pobreza em muitos lugares do mundo e a crise atual de refúgio e migração. É nesse sentido que nossa atualidade, caracterizada pelo chamado capitalismo neoliberal, não é uma integração global genuína e, muito menos, apenas um sistema de organização econômica. A colonialidade nos ensina que a lógica epistêmica do mundo ocidental (colonial, moderno, capitalista, global) e o neoliberalismo são uma nova racionalidade (DARDOT; LAVAL, 2016).

De acordo com Dardot e Laval (2016), uma nova ordem mundial neoliberal atravessa e transforma profundamente as subjetividades. Para esses autores, quando o neoliberalismo é analisado apenas como uma ideologia ou um sistema econômico, a análise acaba por falhar na separação dos sujeitos e das instituições pois tende a enfatizar ações e políticas governamentais como algo separado dos sujeitos. Para eles, analisar o neoliberalismo como uma racionalidade significa analisar a condição e a existência humana, a forma como nos relacionamos uns com os outros e construímos nossas maneiras de ser e viver na chamada "aldeia global".

Nessa atualidade neoliberal, Dardot e Laval (2016) explicam que os sujeitos passam a existir na condição de indivíduos que se auto-governam bem como governam uns aos outros. Pautados no conceito de biopolítica de Foucault, os autores discutem que a governabilidade neoliberal é construída a partir de uma estrutura normativa global que aparentemente se apóia na liberdade de escolha dos indivíduos, mas que, de fato, acaba por orientar suas condutas, práticas e escolhas. É nesse sentido que, segundo Dardot e Laval 
(2016), a racionalidade neoliberal se constitui por técnicas de poder nas condutas humanas e em suas subjetividades.

A nosso ver, essa análise do neoliberalismo como uma racionalidade pode e deve ser aproximada do conceito de colonialidade, pois a compreensão, transformação e ressignificação de nossa existência está no imbricamento das diferenças coloniais e dos modos de vida ocidentais que nos constituem. Como apontamos anteriormente, as técnicas de poder nas condutas humanas não são resultado de quaisquer relações de poder, mas sim de formas de dominação, exploração e conflito que impactam direta e profundamente nossa existência. Dessa forma, diante de um mundo habitado por relações hegemônicas desiguais, diferenças e conflitos, pensar a interculturalidade como uma simples justaposição entre culturas acaba por ocultar as relações de colonialidade, fazendo com que desigualdades e conflitos sejam mantidos e perpetuados.

Para problematizar a complexidade da interculturalidade, nos apoiamos no trabalho de Walsh $(2007$; 2010; 2018), pesquisadora integrante do grupo de pensadores latinoamericano modernidade/colonialidade. Segundo a autora, um primeiro entendimento possível de interculturalidade, que muito tem a compartilhar com o multiculturalismo ${ }^{8}$, é definido por Walsh (2010, p. 77) como "interculturalidade relacional". Essa forma de compreender encontros e relações culturais pauta-se na neutralidade do contato e das trocas culturais e, portanto, desvaloriza os conflitos e os contextos de poder e dominação. O resultado de um processo intercultural relacional está na naturalização das relações de inferioridade e superioridade que emergem das diferenças culturais (WALSH, 2010).

O segundo tipo de interculturalidade, definido pela autora como "funcional", diz respeito à manutenção do status quo, pois promove o encontro com a diversidade se

\footnotetext{
${ }^{8} \mathrm{Na}$ introdução e agora nesta seção utilizamos o termo multiculturalismo de forma distinta do termo interculturalidade. Para nós, multiculturalismo diz respeito aos encontros culturais desatrelados da colonialidade. Interculturalidade, por outro lado, é o termo escolhido pelo grupo latino-americano de modernidade/colonialidade para tratar das relações culturais de forma crítica, considerando as diferenças histórico-sociais inerentes nos sujeitos envolvidos em quaisquer encontros e relações culturais. De acordo com Walsh, "[i]nterculturality here, of course, is not synonymous with multiculturalism, broadly understood in Latin America as the recognition of cultural diversity by governments, states, multilateral institutions, and international nongovernmental organizations, effectuated through a politics of inclusion that, more often than not, is tied to the interests of the dominant order. This multiculturalism was introduced in the late 1980s and the decade of the $90 \mathrm{~s}$ - and continues today - as a component part of the logic of neoliberalism and its project to pacify resistance, fragment movements, and bring the excluded into global capitalism's all-consuming framework and structure" (WALSH, 2018, p. 57).
} 
baseando no diálogo harmônico, na convivência e na tolerância. Esta forma de entender a interculturalidade, como celebratória de um encontro dialógico harmonioso diante da neutralidade da diversidade, sem cor de pele, língua ou religião definida, é, por exemplo, a lógica presente nos recentes documentos europeus, produzidos principalmente no ano do "Diálogo Intercultural” (e.g. COE, 2008). Essa forma de compreensão intercultural se traduz em uma nova estratégia de dominação global que visa o controle do conflito a fim de manter certa estabilidade social, necessária para o desenvolvimento do sistema capitalista neoliberal, cuja lógica inclui agora os povos anteriormente excluídos.

Entretanto, essa integração dos historicamente excluídos acontece dentro da nova razão global do neoliberalismo (DARDOT; LAVAL, 2016) que, como discutimos acima, parece homogeneizar o mundo na chamada "aldeia global", uma vez que compreende todos os aspectos da existência humana de uma única forma e visa, através do discurso da igualdade entre povos, línguas e culturas, não abordar a diferença colonial. De acordo com Walsh (2010), na "interculturalidade funcional", a diferença e a diversidade são reconhecidas em sua existência pois são necessárias para que práticas de inclusão aconteçam; entretanto, práticas de inclusão sem uma compreensão crítica a respeito da razão pela qual práticas de exclusão existem acabam favorecendo o capitalismo global.

Em contraposição, considerando que colonialidade e neoliberalismo se constituem como novas lógicas globais e totalizantes, a interculturalidade pode também ser entendida como lógica e não somente como discurso. Segundo Walsh (2010), a “interculturalidade crítica" coloca a diferença colonial como ponto de partida das relações. Para a autora, é somente pela "interculturalidade crítica" que seremos capazes de construir novos projetos que transformem as estruturas, instituições e relações sociais globalizantes e coloniais, bem como possibilitar novas condições para outras formas de ser, estar, pensar, conhecer, aprender e viver. Trata-se, portanto, de um projeto a ser construído, entendendo a diversidade como uma questão colonial, racial e estrutural (WALSH, 2010).

Nessa terceira perspectiva, a interculturalidade é pensada como proposta de um pensamento outro que se constrói a partir da diferença colonial e confronta as relações hegemônicas estabelecidas (WALSH, 2007) pela lógica colonial/neoliberal. De acordo com o grupo latino-americano modernidade/colonialidade, colocar a diferença colonial como 
ponto de partida significa abandonar o dualismo opressor/oprimido, moderno/primitivo, superior/inferior e configurar novos projetos de cidadania, democracia, direitos humanos, humanidade, relações econômicas (GROSFOGUEL, 2007). Esses projetos outros se constroem a partir da compreensão da colonialidade do poder, do saber e do ser, de seus efeitos sobre as desigualdades do mundo e de suas imbricações no projeto colonial/liberal. Nas palavras de Walsh (2007, p. 57), "la interculturalidad es un paradigma 'otro' que cuestiona y modifica la colonialidad del poder, mientras, al mismo tiempo, hace visible la diferencia colonial" ${ }^{\prime 9}$. Neste sentido, podemos definir um projeto intercultural como um projeto decolonial, pois

[d] ecoloniality, in this sense, is not a static condition, an individual attribute, or a lineal point of arrival or enlightenment. Instead, decoloniality seeks to make visible, open up, and advance radically distinct perspectives and positionalities that displace Western rationality as the only framework and possibility of existence, analysis, and thought (WALSH, 2018, p. 17) ${ }^{10}$.

Pensar "mundos outros" requer, portanto, que estejamos conscientes de como a lógica moderno/colonial nos constitui, ao mesmo tempo em que reconhecemos outros sistemas de saberes que nos permitem acessar outras realidades, existências e racionalidades que podem nos oferecer respostas outras aos desafios e às complexidades de nossa existência. É nesse movimento onto-epistêmico da lógica moderno/colonial que aprendemos sobre quem somos e onde reside a possibilidade real de uma educação intercultural. É pensando nessa necessidade de fazer surgir outros sistemas para além da modernidade/colonialidade que Menezes de Souza (2017) problematiza, no caso abaixo a questão da educação, como poderia ser este otherwise.

[...] the need to think otherwise. For Mignolo (2007), this means de-naturalizing established concepts and conceptual fields and pushing toward an "otherwise than.” For Anzaldúa (2007), what she calls a new mestiza consciousness involves overcoming dichotomies and borderlines separating homogeneities, starting from where one (a non-Western, non-white member of multiple marginalized communities - indigenous, Latino, female, Mexican, bilingual Hispanic) is

\footnotetext{
9 “A interculturalidade é um paradigma 'outro' que questiona e modifica a colonialidade do poder, ao mesmo tempo em que torna visível a diferença colonial” (WALSH, 2007, p. 57. Tradução nossa).

10 "[d] ecolonialidade, nesse sentido, não é uma condição estática, um atributo individual ou um ponto linear de chegada ou iluminação. Ao contrário, a decolonialidade procura tornar visível, se abrir/expandir, avançar em perspectivas e posicionamentos radicalmente distintos que substituem a racionalidade ocidental como a única estrutura e possibilidade de existência, análise e pensamento" (WALSH, 2018, p. 17. Tradução nossa).
} 


\title{
Dossiê Especial FICLLA
}

R E V I S T A X, Curitiba, volume 14, n.5,p. 82-105, 2019

\begin{abstract}
located in order to rethink, reread and rewrite a world organized otherwise.[...] However, the possibility for a critical transcultural literacy education lies in taking stock of the learned and inherited resources one has available (language, knowledge, and values), understanding why these resources are there and where they came from, appreciating the restrictions they impose on the possibility of creating and perceiving new meaning, and finally making the necessary adjustments to these available resources in order to make possible the appearance of new meanings, new understandings - that is, in order to think otherwise (MENEZES DE SOUZA, 2017, p. 275-276) ${ }^{11}$.
\end{abstract}

Imersas nas reflexões propostas pelo grupo latino-americano de modernidade/colonialidade, passamos a tratar do impacto desses conceitos e teorias também no campo da educação, principalmente na atualidade neoliberal global na qual políticas e práticas de internacionalização da Educação Superior têm sido cada vez mais estabelecidas e sem o devido questionamento sobre a lógica colonial/neoliberal que as constitui. A nosso ver, promover encontros interculturais e internacionais sem considerar a colonialidade é trabalhar a favor do capitalismo neoliberal global, ampliando as relações desiguais de poder entre raças, gêneros, saberes, culturas, línguas, etc. Para melhor exemplificar nossas preocupações enquanto educadoras e problematizar os desafios, complexidades e possibilidades que percebemos nas práticas de interculturalidade e de internacionalização, passamos para a segunda parte deste artigo.

\section{SITUAÇÕES PROBLEMATIZADORAS: UM EXERCÍCIO DE REFLEX̃̃O SOBRE A MODERNIDADE/COLONIALIDADE}

Conforme mencionamos nas considerações iniciais, a seguir apresentamos duas situações problematizadoras que servem como possibilidade de reflexão a respeito dos aspectos que enfatizamos neste texto, ou seja, de questões diretamente ligadas ao mundo

\footnotetext{
11 “[...] a necessidade de pensar o contrário. Para Mignolo (2007), isso significa desnaturalizar conceitos estabelecidos e campos conceituais e avançar para um "diferente de". Para Anzaldúa (2007), o que ela chama de uma nova consciência mestiza, envolve superar dicotomias e limites separando homogeneidades, começando de onde (um membro não-ocidental e não-branco de várias comunidades marginalizadas indígena, latina, feminina, mexicana, hispânica bilíngue) está localizado para repensar, reler e reescrever um mundo organizado de outra forma. [...] No entanto, a possibilidade de uma educação transcultural crítica consiste em fazer um balanço dos recursos aprendidos e herdados que temos disponíveis (idioma, conhecimentos e valores), entender por que esses recursos existem e de onde vieram, apreciando as restrições que impõem à possibilidade de criar e percebendo um novo significado e, finalmente, fazendo os ajustes necessários desses recursos disponíveis, a fim de possibilitar o surgimento de novos significados, novos entendimentos - ou seja, para pensar o contrário" (MENEZES DE SOUZA, 2017, p. 275-276. Tradução nossa).
} 
moderno/colonial/neoliberal. Acreditamos que esses exemplos possam nos ajudar a fazer outros sentidos dos conceitos apresentados na seção anterior, bem como deixar mais palpáveis e visíveis as complexidades de nossas vidas diárias, de nossos encontros uns com os outros no mundo e de como somos sujeitos no/com o mundo (FREIRE, 2000). As situações problematizadoras usadas aqui foram livremente produzidas a partir de narrativas conhecidas por nós e organizadas para a "Roda de Conversa" no FICLLA quando buscamos uma experiência de diálogo horizontal com os participantes que estiveram no evento conosco.

\title{
Situação 1: a experiência de mobilidade acadêmica de Mariana
}

\begin{abstract}
Mariana, estudante brasileira, foi cursar graduação sanduíche nos Estados Unidos. Ela se sente extremamente feliz e orgulhosa pela oportunidade de ter sido selecionada, enquanto muitos outros alunos não tiveram a mesma chance. Ao ser questionada sobre a interação com seus colegas estadunidenses, Mariana destacou a oportunidade de interagir em um ambiente multicultural e diverso, uma vez que conheceu, além de colegas estadunidenses, estudantes de vários países. Os contatos interpessoais de Mariana são estritamente ligados à sala de aula e aos colegas internacionais no âmbito desse intercâmbio. Mariana não costuma ser questionada sobre o Brasil, além das perguntas que contribuem para alimentar o estereótipo de brasileira sensual, amante de carnaval e moradora de país tropical ao sul do Equador.
\end{abstract}

A primeira situação que propomos refletir está relacionada ao que atualmente tem sido chamado de internacionalização. Em contextos de Educação Superior, tem sido cada vez mais comum falar em internacionalização e um dos desafios recorrentes está em compreender o que significa exatamente internacionalizar a universidade. No caso das universidades públicas no Brasil, sem pretensão de homogeneizá-las, sabendo de suas particularidades em âmbitos regionais/locais e governamentais (se municipal, estadual ou federal), parece haver uma vontade comum por parte de suas comunidades e dirigentes de se tornarem instituições internacionais, ou ainda de integrar um possível cenário global da Educação Superior na "aldeia global". Tal vontade transparece em planos de desenvolvimento institucionais ${ }^{12}$ ou planejamentos estratégicos das universidades, bem

\footnotetext{
${ }^{12}$ Com o intuito de exemplificar a presença dessa vontade institucional de internacionalização, aqui está uma notícia sobre o plano institucional de internacionalização da UFPR. Disponível em: https://www.ufpr.br/portalufpr/noticias/cepe-aprova-plano-institucional-de-internacionalizacao-da-ufpr/. Acesso em: 14 ago. 2019.
} 
como em editais e diretrizes publicadas por agências de fomento ${ }^{13}$, que definem a internacionalização como uma condição sine qua non da universidade na atual globalização.

Para que essa vontade e condição de integração se concretize e as universidades participem da internacionalização, uma busca constante por ações que fomentem o que se entende ser a internacionalização acaba por ocorrer. Algumas dessas ações envolvem, por exemplo, a promoção de atividades internacionais na universidade, a ampliação da mobilidade acadêmica de estudantes e professores, a ampliação de parcerias e projetos internacionais com instituições em outros países, a criação de novas iniciativas de pesquisa e de programas acadêmicos internacionais, a inclusão de uma dimensão global e intercultural nos currículos locais e no processo de ensino-aprendizagem dos alunos e, ainda, o fornecimento de educação para outros países através de formatos distintos dos locais como no caso de franquias, de campi internacionais e/ou de ensino à distância (KNIGHT, 2005). Essas ações, de maneira geral, estão atreladas ao entendimento de que o objetivo mais relevante da internacionalização, ou da educação internacional, está em contribuir para um mundo interconectado e para a troca de conhecimento (KNIGHT, 2004). Além disso, entende-se que a internacionalização seja uma oportunidade de interconexão, de troca de conhecimento e de aprimoramento da educação, ou seja, a internacionalização traz melhoria na qualidade da educação (KNIGHT; WIT, 1995).

A nosso ver, entretanto, outros aspectos da internacionalização deveriam também ser levados em consideração, principalmente em relação à compreensão de globalização que parece desatrelada do conceito de colonialidade. Se, por um lado, a internacionalização pode beneficiar a Educação Superior, por outro parece haver relutância por parte de pesquisadores e dirigentes institucionais de se engajarem com os paradoxos e desafios mais inquietantes que surgem da promoção e propagação da internacionalização (STEIN et. al., 2016). Grande parte das pesquisas sobre internacionalização constata os efeitos da globalização e da internacionalização, sem chegar a uma análise mais complexa da relação entre os dois fenômenos (BECK, 2012). Desse modo, a racionalidade mercadológica, as

\footnotetext{
${ }^{13}$ Para exemplificar diretrizes de agências de fomento, compartilhamos o link do Programa Institucional de internacionalização - CAPES/PrInt. Disponível em: https://capes.gov.br/bolsas-e-auxilios-internacionais lcapes-print. Acesso em: 14 ago. 2019.
} 
lógicas de competitividade e a visão da educação como produto, aspectos que fundamentam o imbricamento entre globalização e internacionalização, acabam em uma zona de invisibilidade (BECK, 2012). Esquece-se, portanto, que a internacionalização da educação se tornou uma alternativa lucrativa, criada e operada por governos e instituições para atender às exigências da globalização neoliberal (ALTBACH, 2004). Segundo Rhee (2009),

\begin{abstract}
[t]he field of international education is one of the most depoliticized educational discussions and analyses in educational discourse. Neither dominant academic research nor popular, journalistic literature (or sources) seriously consider issues of inequalities, marginalization, and exclusion that are present in international education. Indeed, international education often is framed as "a tradable commodity" which is "an inevitable outcome of globalization" (Sidhu, 2006, p. vii). This market based framing of international education shapes how university administrators, policy makers, academics, parents, and students make sense of international education. International student-consumers desire certain brands of education, shop for them according to their preference and budget/qualification, and become loyal customers who develop certain identities based on their affiliations with those brands. In this globalized world, it is assumed that these individual customers make allegedly free educational choices ultimately to enhance their competitiveness as a global/local workforce. This orientation is a manifestation of neoliberal discourse and practice of globalization, which tends to "explain away privilege and subordination as well as justify public divestment and privatization" (DAZA, 2006, p. 554 apud RHEE, 2009, p. 56) ${ }^{14}$.
\end{abstract}

É neste cenário que Mariana, a estudante brasileira que foi aos Estados Unidos, se encontra. Ela faz parte das estatísticas que apontam um fluxo de mobilidade estudantil dinâmico e desigual entre universidades do Norte e do Sul Global (OECD, 2014; MARGINSON, 2008). Nosso exercício reflexivo com a mobilidade de Mariana começa em pensarmos como a colonialidade atravessa a experiência vivida pela aluna. Essa não é uma

\footnotetext{
14 "O campo da educação internacional é um dos mais despolitizados nas discussões e análises educacionais no discurso educacional. Nem a pesquisa acadêmica dominante, nem a popular e nem a literatura jornalística (ou outras fontes) consideram seriamente questões de desigualdades, marginalização e exclusão presentes na educação internacional. De fato, a educação internacional geralmente é enquadrada como "uma mercadoria comercializável" por ser "um resultado inevitável da globalização" (Sidhu, 2006, p. vii). Esse enquadramento da educação internacional, baseado no mercado, molda como administradores de universidades, elaboradores de políticas, acadêmicos, pais e alunos entendem a educação internacional. Estudantes-consumidores internacionais desejam determinadas marcas de educação, as compram de acordo com suas preferências e orçamento/qualificação e se tornam clientes fiéis que desenvolvem certas identidades com base em suas afiliações nessas marcas. Nesse mundo globalizado, supõe-se que esses clientes individuais façam escolhas educacionais supostamente gratuitas para aumentar sua competitividade como força de trabalho global/local. Essa orientação é uma manifestação do discurso neoliberal e da prática de globalização, que tende a explicar privilégios e subordinação, bem como justificar o desinvestimento e a privatização em âmbito público" (DAZA, 2006, p. 554 apud RHEE, 2009, p. 56. Tradução nossa).
} 
pergunta simples, nem de ser formulada nem de ser respondida. O que percebemos em nossos contextos profissionais com certa frequência, entretanto, é que a experiência de mobilidade internacional de alunos faz outros aspectos transparentes e não trata da colonialidade.

Para exemplificar, ressaltamos aqui três desses aspectos. Primeiro, falar em mobilidade significa falar em proficiência linguística, ou seja, Mariana torna-se responsável por comprovar conhecimentos de inglês por meio de currículo, certificação e/ou entrevista antes de se qualificar para uma vaga de mobilidade acadêmica. Com isso ressaltamos que Mariana precisa comprovar que possui determinados saberes, exigidos e legitimados, antes de receber permissão para embarcar e transitar nesta experiência internacional. Um segundo aspecto poderia ser definido como a preparação burocrática, pois Mariana precisa providenciar documentos, vistos, formulários, bem como entender como as atividades realizadas na universidade estadunidense devem ser contabilizadas em seu histórico escolar brasileiro ou agregadas em seu currículo, por exemplo. Isso nos mostra como Mariana integra as lógicas da modernidade e se seus saberes, cultura, língua, raça, gênero serão recebidos legitimamente em uma universidade estrangeira à sua, se serão questionados e invisibilizados, bem como se sofrerão uma supervalorização após seu retorno ao Brasil. É significativo perceber que Mariana participa de uma política de mobilidade acadêmica previamente informada pela colonialidade e que, portanto, legitima e valoriza alguns saberes em detrimento de outros. Esse segundo aspecto nos leva ao último que mencionamos aqui, o qual chamamos de viés acadêmico-científico, ou seja, diz respeito às "escolhas" de Mariana no momento de decisão sobre qual país se candidatar para mobilidade e quais disciplinas/atividades realizar na universidade estrangeira, por exemplo. Todas essas escolhas estão também atreladas aos saberes que mais lhe agregam valor dentro das lógicas mercadológicas, colonial e neoliberal, expressas em currículos, vagas de emprego e futuros processos de seleção acadêmica ou profissional.

O que nos deixa intrigadas é o fato da vivência intercultural de Mariana, entretanto, parecer alocada em uma zona de invisibilidade da internacionalização. Se Mariana vivencia alguma situação de racismo ou marginalização, por exemplo, seus relatos, afetos e emoções a esse respeito acabam em narrativas menos importantes do que a valorização dos saberes 
acadêmico-científicos que ela adquiriu com a oportunidade de estudos no Norte Global. Outras aprendizagens, como por exemplo, se seus estereótipos em relação à língua inglesa, à sua língua materna, ao povo estadunidense, bem como ao Brasil, ou a compreensão daquilo que ela entende ser um país multicultural e diverso, parecem menos significativas do que os saberes acadêmico-científicos adquiridos. A aluna integra, portanto, o mercado global da educação internacional como bem nos explicou Rhee (2009). A razão da existência de Mariana é constituída por um corpo ocidentalizado, fruto da modernidade/colonialidade que responde às necessidades mercadológicas.

Essas reflexões nos levam a pensar na complexidade com que ações de internacionalização, bem como a própria crença de que existam práticas genuínas de troca e de interconexão entre os envolvidos em ações de internacionalização, encontram-se atualmente. Entendemos que esse processo de internacionalização que se volta ao mercado e aos valores legitimados nas sociedades ocidentais acaba por naturalizar hierarquias raciais existentes e desigualdades econômicas (STEIN et al., 2016). Trata-se de uma marca estruturante e um modo único de ser no mundo ocidental que legitima certas perspectivas de vida e de saber em detrimento de outras (STEIN et al., 2016). Uma experiência de mobilidade que não inclui em sua agenda a interculturalidade corre o risco de apenas alimentar a lógica da colonialidade e a racionalidade neoliberal, perdendo a oportunidade de aprendizagem sobre os limites, complexidades e desafios onto-epistêmicos do mundo.

\section{Situação 2: a experiência de migração de Juana}

Juana, venezuelana, engenheira petroquímica, com mestrado na área, reside em Boa
Vista, Roraima, não conseguiu se inserir no mercado de trabalho e teve que trabalhar
como 'oitchenta', prostituta chamada assim porque cobram oitenta reais no programa.
Juana, na Venezuela, trabalhava em uma empresa, morava em um apartamento de três
quartos, ia para academia e gostava de sair em alguns barzinhos com os amigos. Quando
atravessou a fronteira, percebeu que a única posse dela era o próprio corpo que agora lhe
tira a fome. "Saí pelas ruas procurando trabalho. Acabei pedindo dinheiro e, depois de
dias, comecei a fazer isso", conta Juana que saiu da Venezuela com planos de trabalhar
no Brasil. "Não tenho mais opções. E de algo tenho que sobreviver." Juana demonstra a
frustração e a ansiedade em um choro que ainda tenta conter.

A crise econômica e humanitária da Venezuela provocou um fluxo migratório em contínuo aumento nos países da América Latina, entre os quais o Brasil se coloca em quinto

DELL'OLIO; MARTINEZ, 2019 
lugar (OIM, 2019) ${ }^{15}$. Embora se trate de países da mesma região geograficamente, no nível econômico e institucional, esta proximidade tem pouco efeito. Quando chegam ao Brasil, os imigrantes venezuelanos enfrentam problemas de reconhecimento educacional com seus diplomas, dificuldades no uso dos serviços públicos brasileiros e de inserção no mundo do trabalho, embora, como aponta uma pesquisa da Fundação Getúlio Vargas (2018), boa parte deles (32\%) tenha ensino superior completo e mais da metade (60\%) estivesse empregada antes de migrar para o Brasil.

Baseando-nos nestes dados e pensando o atual cenário migratório mundial, podemos pensar como a fluidez, considerada uma das principais características da tal "aldeia global", serve aos interesses econômicos construídos pela lógica colonial/neoliberal: enquanto recursos financeiros e mercadorias atravessam fronteiras e países, as subjetividades dos seres humanos, protagonistas de viagens migratórias, são desconstruídas e reconfiguradas pelo atravessamento de fronteiras. Isso acontece pois as fronteiras não são limites nem neutros nem naturais, mas sócio-historicamente construídos pelas relações do mundo moderno/colonial/neoliberal, como podemos observar nas diferenças entre a mobilidade de Mariana, relatada na primeira situação, e agora de Juana. Isso significa que esses limites filtram corpos e subjetividades, permitindo ou impedindo o movimento, de acordo com processos de co-criação do sistema-mundo (DELL'OLIO, 2018).

Para exemplificar, considerando os dados aqui compartilhados sobre a migração venezuelana, podemos afirmar, em primeiro lugar, que a decisão de Juana em migrar para o Brasil não foi livre, mas provocada por uma crise político-econômica que não deixou outras possibilidades. Segundo, há de se considerar que atravessar a fronteira para chegar ao Brasil desnuda os sujeitos migratórios de suas vidas, deixando-os apenas com seus próprios corpos. Corpos esses em que estão inscritas suas proveniências: venezuelana, migrante, mulher. Se por um lado, o Brasil, através de organizações como a ACNUR ${ }^{16}$, oferece cuidados básicos a estes corpos, o sistema político-econômico reserva espaços

\footnotetext{
15 Dados da Organização Nacional para as Migrações. Disponível em: https://www.acnur.org/portugues /2019/06/07/numero-de-refugiados-e-migrantes-da-venezuela-ultrapassa-4-milhoes-segundo-o-acnur-e-a-oim/ Acesso em: 14 ago. 2019.

${ }^{16}$ ACNUR é a Agência da ONU para Refugiados. Disponível em: https://www.acnur.org/portugues/. Acesso em: 14 ago. 2019.
} 
determinados e delimitados a estes migrantes.

Podemos, portanto, afirmar que as identidades de fronteiras são performativas (BUTLER, 2005), pois o sujeito não tem uma identidade fixa que carrega com ele/ela uma vez que sua identidade é co-criada através de relações que moldam determinadas subjetividades. Os atos e gestos permitidos a determinados corpos inserem-se nas relações desiguais da colonialidade, ou seja, o "sistema-mundo europeu/euro-norte americano capitalista/patriarcal moderno/colonial" mantém as relações hierárquicas de trabalho e étnico-raciais em uma dualidade centro/periferia (CASTRO-GÓMEZ; GROSFOGUEL, 2007), necessária para alimentar o sistema de exploração neoliberal. Como mostramos anteriormente, as exclusões provocadas pelas hierarquias epistêmicas, raciais e de gênero se originaram na época do colonialismo, mas continuam tendo um papel relevante na atualidade.

Desse modo, a colonialidade, elemento constitutivo do padrão mundial capitalista, impõe uma classificação étnico-racial da população do mundo e atua não somente no plano material, mas também subjetivo e na vida diária dos sujeitos (QUIJANO, 2007). O imbricamento do sistema moderno/colonial com o neoliberal/capitalista alimenta o falso entendimento de que os sujeitos são livres autores das próprias existências e podem, portanto, se deslocar livremente em busca de novas condições de trabalho e de vida. A situação de Juana aponta, porém, os limites do sistema-mundo no qual estamos inseridos e de como sua ação sobre os sujeitos seja totalizante.

Dardot e Laval (2016), ao falarem de "racionalidade neoliberal", evidenciam o poder organizativo e estruturante do neoliberalismo como razão do capitalismo contemporâneo, "plenamente assumido como construção histórica e norma geral de vida" (DARDOT; LAVAL, 2016, p. 17). A racionalidade neoliberal, portanto, não se limita à esfera econômica, mas integra todas as esferas da existência humana; o discurso neoliberal baseia-se na capacidade de ser empresário de si mesmo, eximindo a sociedade de qualquer responsabilidade sobre o destino de cada ser. O desemprego, o aumento da pobreza e desigualdade, as crises econômicas das últimas décadas, por exemplo, não são vistos como problemas estruturais do sistema moderno capitalista/neoliberal, mas como uma deficiência de cada indivíduo que é deficitário em suas capacidades e requisitos exigidos pelo mercado 
de trabalho.

Ao pensarmos criticamente a respeito dessa lógica que sustenta a globalização e a ideia de "aldeia global", e considerando as relações entre neoliberalismo e colonialidade, é possível entender como as novas identidades sociais e as relações de poder desiguais do mundo moderno capitalista/neoliberal se instalaram e se reproduzem a partir dessas relações de poder atravessadas pela dominação colonial (QUIJANO, 2007). Segundo Quijano, "[1]a racialización de las relaciones de poder entre las nuevas identidades sociales y geo-culturales fue el sustento y la referencia legitimadora fundamental del carácter eurocentrado del patrón de poder, material e intersubjetivo. Es decir, de su colonialidad" (QUIJANO, 2007, p. 119) ${ }^{17}$.

É a partir desta leitura da geopolítica mundial e considerando as diferentes compreensões de mobilidade, tanto pela narrativa de Mariana, quando entra pela porta da frente da universidade estadunidense, quanto pela narrativa de Juana, que possivelmente carregará ao longo de sua vida cicatrizes de sua chegada ao Brasil, que abordamos a interculturalidade. Sejam esses movimentos migratórios ou para mobilidade educacional, entendemos que ambos proporcionam encontros com o outro, um outro marcado por diferenças raciais, linguísticas e culturais, isto é, diferenças epistêmicas que constroem mundos diferentes. Ao considerar a interculturalidade como encontros harmoniosos, entre sujeitos não marcados, acaba-se por ocultar a violência da relação com o outro, seja este outro ser humano ou o sistema-mundo no qual estamos inseridos.

A situação da Juana evidencia a violência da migração, bem como sua imprevisibilidade. Primeiramente, Juana é forçada a deixar sua vida aparentemente estável e, em seguida, ao atravessar a fronteira, a vender seu corpo, o único recurso que ainda lhe pertencia. Mariana, em uma situação muito mais confortável, responde às lógicas neoliberais, não irá vender seu corpo, mas certamente precisará se adequar à lógica epistêmica ocidental. Podemos, assim, afirmar que a estrutura neoliberal não abre espaços de liberdade ou livre circulação, mas sim limita e força os sujeitos em formas de vida carregadas de violências e criadas pelo imbricamento de fatores históricos, político-

\footnotetext{
17 “A racialização das relações de poder entre as novas identidades sociais e geo-culturais foi a base e a referência legitimadora fundamental do caráter eurocentral do padrão de poder, material e intersubjetivo, ou seja, de sua colonialidade" (QUIJANO, 2007, p. 119. Tradução nossa).
} 
econômicos, de raça, gênero, língua e cultura.

Considerar, contudo, a performatividade dos sujeitos como co-criação significa também entender que existem espaços de ação dos sujeitos, pois os encontros interculturais podem emergir "in-between spaces" que desestabilizam e reconfiguram as certezas das ordens pré-determinadas (GHILARDI, 2015). Para tanto, faz-se necessário pensar a interculturalidade a partir de uma postura ética, ou seja, não somente ter consciência de como a modernidade/colonialidade nos constitui como sujeitos no mundo, mas também pensar ações que se baseiam em racionalidades outras a respeito da lógica moderna/colonial. Acreditamos que, partindo de outras epistemes, podemos abrir espaços para que encontros interculturais transformem e reconfigurem as "ordens" preestabelecidas, transformando assim as lógicas de "comodificação" ou "exotização" do outro e de nós mesmos.

\section{CONSIDERAÇÕES FINAIS}

Ao longo deste texto, buscamos refletir sobre as implicações da colonialidade e da racionalidade neoliberal a partir das situações vividas por Mariana e Juana. Apesar de ambas as narrativas tratarem de mobilidade, quando relatadas, elas seriam facilmente desconectadas uma da outra. A primeira seria identificada, provavelmente, como exemplo de sucesso, mérito e oportunidade, uma vez que Mariana é candidata à inclusão social. Juana, por outro lado, representaria, possivelmente, o fracasso e a tragédia, tornando-se candidata à exclusão. $\mathrm{O}$ que essas explicações sobre as experiências vividas por Mariana e Juana têm em comum está no apagamento da colonialidade. Ambas são mulheres em experiência intercultural e internacional, com motivações e necessidades distintas, e marcadas pelas lógicas da modernidade/colonialidade.

Sousa Santos (2007) nos diria que há uma linha abissal atravessando essas duas narrativas; uma linha que organiza a vida e os modos de ser, saber e sentir no mundo ocidental, a partir daquilo que o ocidente torna (in)visível, isto é, enquanto a história de Mariana é visível, a de Juana é invisível. Segundo o autor, a linha abissal é necessária na lógica do sistema-mundo ocidental, pois é preciso que uma parte da humanidade seja negada, considerada subumana, para que a outra parte se afirme como universal. Isso 
significa que a trajetória de Mariana é percebida como "natural" enquanto a trajetória de Juana é apagada, se encontrando do outro lado da linha.

Como tentamos problematizar ao longo do texto, as duas situações são resultado dos desafios e das complexidades que emergem da colonialidade e da racionalidade neoliberal que nos constitui. Diante da impossibilidade de zerarmos a História e/ou apagarmos as diferenças coloniais, o que fazer com essas narrativas? Como lidar com a colonialidade que nos constitui? Há possibilidades para além dos desafios e das complexidades? Se estamos imbuídos em uma trama histórico-social moderna/colonial, situada em um sistema-mundo constituído pela lógica capitalista/neoliberal, em corpos marcados por raça, gênero, cultura, língua, como podemos construir outras relações em espaços interculturais?

Não existem respostas derradeiras para essas perguntas; não há como saber que mundo seria alternativo ao moderno/colonial. Temos aprendido com os pensadores latinoamericanos que é preciso construir um projeto decolonial, distinto da racionalidade atual, com força suficiente para interromper as violências produzidas pela linha abissal que dá existência ao mundo ocidental. O que partilhamos aqui, à guisa de conclusão, é o que Menezes de Souza (2019) ${ }^{18}$ chama de estratégia crítica decolonial. Para o autor, essa estratégia consiste em três etapas: primeiro, identificar, interrogar e interromper a colonialidade e o pensamento ocidental; segundo, pensar a partir das margens da colonialidade, com pensamentos de fronteira, por exemplo; e, terceiro, buscar a diversidade epistêmica e ontológica, ou seja, outras formas de ser, sentir, saber, aprender, viver.

A nosso ver, essas estratégias apontam possibilidades éticas necessárias em um projeto decolonial. Isso significa estarmos abertos para aprender sobre onde estamos situados, de como a modernidade/colonialidade nos constitui e como, simultaneamente, constituímos o mundo. Essa abertura precisa também se dar em coletividade, pois, como apontamos anteriormente, o livre-arbítrio dos sujeitos é moldado por seus contextos histórico-sociais que necessitam de transformação. Podemos sim identificar privilégios individuais, por exemplo, e interromper práticas que a nosso alcance estiverem, mas, ao mesmo tempo, reconhecemos a importância de políticas públicas, educacionais, sociais, linguísticas, pois ações coletivas e institucionais poderão auxiliar na construção de outras

\footnotetext{
${ }^{18}$ Conferência de Encerramento da II Jornada Internacional de Linguística Aplicada Crítica, UnB, 2019.
} 


\section{Dossiê Especial F ICLLA}

REVISTA X, Curitiba, volum e 14, n.5,p. 82-105, 2019

lógicas onto-epistêmicas. Mariana e Juana, por exemplo, são perfeitamente capazes de identificar e interrogar a colonialidade que as constitui; entretanto, as opções que ambas possivelmente terão para interromper a colonialidade poderão não ser as mesmas.

\section{REFERÊNCIAS:}

ALTBACH, P. Globalization and the university: myths and realities in an unequal world. Tertiary Education and Management, v. 10, n.1, p. 3-25, 2004.

BECK, K. Globalization/s: Reproduction and Resistance in the Internationalization of Higher Education. Canadian Journal of Education, v. 35, n. 3, p. 133-148, 2012.

BUTLER, J. Giving an Account of Oneself. New York: Fordham University Press, 2005.

CASTRO-GÓMEZ, S.; GROSFOGUEL, R. Prólogo. Giro decolonial, teoría crítica y pensamiento heterárquico. In: CASTRO-GOMÉZ, S.; GROSFOGUEL, R. El giro decolonial: reflexiones para una diversidad epistémica más allá del capitalismo global (compiladores). Bogotá: Siglo del Hombre Editores, Universidad Central, Instituto de Estudios Sociales Contemporáneos y Pontificia Universidad Javeriana, Instituto Pensar, p. 09-24, 2007.

COUNCIL OF EUROPE (COE). White Paper on Intercultural Dialogue: "Living Together As Equals in Dignity”. Strasbourg, 2008.

DARDOT, P.; LAVAL, C. A nova razão do mundo: ensaio sobre a sociedade neoliberal. São Paulo: Boitempo, 2016.

DELL'OLIO, F. Encontros interculturais entre fronteiras: corpos e afetos migrantes. Tese (Doutorado em Estudos Lingüísticos e Literários em Inglês) - Faculdade de Filosofia, Letras e Ciências Humanas, Universidade de São Paulo, São Paulo, 2018. Acesso em: 14 ago. 2019.

FGV DAPP. Desafio Migratório em Roraima. Repensando a política e gestão da migração no Brasil. Rio de Janeiro, 2018. Disponível em: http://dapp.fgv.br/wp-content/uploads /2018/03/Desafio-migrato\%CC\% 81rio-Roraima-policy-paper.pdf. Acesso: 14 ago. 2019.

FREIRE, P. Pedagogia da autonomia. 14 ed. São Paulo: Paz e Terra, 2000.

GHILARDI, M. The line of the arch: intercultural issues between aesthetics and ethics. Milano: Mimesis, 2015.

GROSFOGUEL, R. Descolonizando los universalismos occidentales: el pluri-versalismo transmoderno decolonial desde Aimé Césaire hasta los zapatistas. In: CASTRO-GOMÉZ, S.; GROSFOGUEL, R. El giro decolonial: reflexiones para una diversidad epistémica más 
allá del capitalismo global (compiladores). Bogotá: Siglo del Hombre Editores, Universidad Central, Instituto de Estudios Sociales Contemporáneos y Pontificia Universidad Javeriana, Instituto Pensar, p. 63-78, 2007.

HARAWAY, D. Situated Knowledges: The Science Question in Feminism and the Privilege of Partial Perspective. Feminist Studies, v. 14, n. 3, p. 575-599, 1988.

KNIGHT, J. An Internationalization Model: Responding to New Realities and Challenges. In: WIT, H. (ed.) Higher Education in Latin America: The International Dimension. The International Bank for Reconstruction and Development. The World Bank, Washington, p. 01-38, 2005.

KNIGHT, J. Internationalization remodeled: Definition, approaches, and rationales. Journal of Studies in International Education, n.8, v.1, p. 05-31, 2004.

KNIGHT, J.; WIT, Hans de. Strategies for internationalisation of higher education: historical and conceptual perspectives. In: WIT, H. (ed.) Strategies for internationalisation of higher education: a Comparative Study of Australia, Canada, Europe and the United States of America. Amsterdam: European Association for International Education (EAIE) in cooperation with the Programme on Institutional Management in Higher Education (IMHE) of the Organisation for Economic Cooperation and Development (OECD) and the Association of International Education Administrators (AIEA), p. 5-32, 1995.

MALDONADO-TORRES, Nelson. Sobre la colonialidad del ser: contribuciones al desarrollo de un concepto. In: CASTRO-GÓMEZ, S.; GROSFOGUEL, R. El giro decolonial: reflexiones para una diversidad epistémica más allá del capitalismo global (compiladores). Bogotá: Siglo del Hombre Editores, Universidad Central, Instituto de Estudios Sociales Contemporáneos y Pontificia Universidad Javeriana, Instituto Pensar, p. 127-168, 2007.

MARGINSON, Simon. Global field and global imagining: Bourdieu and worldwide higher education. British Journal of Sociology of Education, v. 29, n.3, p. 303-315, 2008.

MARTINEZ, J. Z. Entre fios, pistas e rastros: os sentidos emaranhados da internacionalização da Educação Superior. Tese (Doutorado em Estudos Linguísticos e Literários em Inglês) - Faculdade de Filosofia, Letras e Ciências Humanas, Universidade de São Paulo, São Paulo, 2017. Acesso em: 14 ago. 2019.

MENEZES DE SOUZA, L. M. Multiliteracies and Transcultural Education. In: GARCÍA, O.; FLORES, N.; SPOTTI, M. (Eds.). Oxford University Press. The Oxford Handbook of Language and Society. New York, NY: Oxford University Press, p. 275-276, 2017.

MIGNOLO, W. Coloniality: The Darker Side of Modernity, 2007. Disponível em: https://www.macba.cat/PDFs/walter_mignolo_modernologies_eng.pdf. Acesso em: 14 ago. 2019. 


\section{Dossiê Especial FICLLA}

REVISTA X, Curitiba, volum e 14, n.5,p. 82-105, 2019

MIGNOLO, W. Geopolitics of Sensing and Knowing On (De)Coloniality, Border Thinking, and Epistemic Disobedience. Confero, vol. 1, n. 1, 2013, p. 129-150. Disponível em: http://www.confero.ep.liu.se/issues/2013/v1/i1/130312b/confero13v1i1129.pdf Acesso em: 14 ago. 2019.

OECD. Education at a Glance 2014: Highlights, OECD Publishing, 2014.

QUIJANO, A. Colonialidade, poder, globalização e democracia. Revista Novos Rumos, v. 17, n. 37, p. 4-25, maio/ago, 2002.

QUIJANO, A. Coloniality and Modernity/Rationality. Cultural Studies, v. 21, n. 2, p. 168$178,2007$.

RHEE, J. International Education, The New Imperialism, and Technologies of the Self: Branding the Globally Educated Elite. Multicultural Education Review, vol. 1, n. 1, p. 55$82,2009$.

SOUSA SANTOS, B. A Gramática do Tempo: Para uma Nova Cultura Política. São Paulo: Cortez, 2010.

SOUSA SANTOS, B. Para além do pensamento abissal. Novos Estudos, 79, novembro, 2007. Disponível em: http://www.scielo.br/pdf/nec/n79/04.pdf. Acesso em: 14 ago. 2019.

STEIN, S. et al. Towards Different Conversations About the Internationalization of Higher Education. Comparative and International Education. Éducation Comparée et Internationale, vol. 45, n. 1, 2016.

WALSH, C. Interculturalidad Crítica y Educación Intercultural. In: VIANA, J. Construyendo Interculturalidad Crítica, III CAB, Instituto Internacional de Integración del Convenio Andrés Bello: La Paz, Bolívia, p.75-96, 2010.

WALSH, C. Interculturalidad y colonialidad del poder. Un pensamiento y posicionamiento "otro" desde la diferencia colonial. In: CASTRO-GÓMEZ, S.; GROSFOGUEL, R. (eds.). El giro decolonial: Reflexiones para una diversidad epistémica más allá del capitalismo global. Bogotá: Siglo del Hombre Editores; Universidad Central, Instituto de Estudios Sociales Contemporáneos y Pontificia Universidad Javeriana, Instituto Pensar, p. 47-62, 2007.

WAlSh, C.; MIGNOLO, W. On Decoloniality: Concepts, Analyitics, Praxis. Duke University Press, Durham, 2018. 